\title{
СРАВНИТЕЛЬНАЯ ОЦЕНКА ВЛИЯНИЯ ИНГИБИТОРОВ ЦОГ-2 НА ТЕЧЕНИЕ СИНДРОМА ПЛЕЧЕЛОПАТОЧНОГО ПЕРИАРТРОЗА
}

\author{
Ягубов В.А. \\ «Саглам Аиле» Медищинский Центр
}

В настоящее время принято считать, что плечелопаточный периартроз развивается вследствие дистрофических изменений в мягких тканях, окружающих плечевой сустав на фоне длительно существующих признаков дегенеративно-дистрофического поражения шейного отдела позвоночника клиникой выраженного повреждения нервных корешков, а также вследствие травм плечевого пояса или самого сустава. Необходимо отметить, что плечелопаточный периартроз - состояние, трудно поддающееся коррекции. Зачастую, одной из причин этого является длительность существования заболевания до момента начала коррекционного лечения. Возникающий на начальных стадиях болезни очаговый некроз или частичные разрывы сухожильных волокон и асептическое воспаление сухожилий и серозных сумок, приводит на поздних стадиях к фиброзным изменениям, ведущим к развитию контрактур и формированию синдрома «замороженного плеча».

Клинические проявления плечелопаточного периартроза складываются из болей в плече, усиливающихся в ночное время, болезненности при пальпации и отведении плечевого сустава, а также ограничение подвижности плечевого сустава в разных плоскостях. Острый период болевого синдрома длится до 3-х месяцев, затем происходит хронизация боли, зачастую, протекающая на фоне длительного ограничения подвижности плечевого сустава.

Основополагающей тактикой лечения плечелопаточного периартроза в острой стадии является купирование болевого синдрома. С этой целью широко используются нестероидные противовоспалительные средства (НПВС), в большинстве случаев, подбор которых некорректно осуществляется врачами, что приводит к серь- езным изменениям желудочно-кишечного тракта. Учитывая длительность применения НПВС при данной патологии, предпочтение отдается селективным ингибиторам ЦОГ-2 в связи с их выраженной противовоспалительной и анальгезирующей активности, безопасности использования и наименьшему числу побочных эффектов.

Целью данного исследования явилось изучение терапевтического влияния молекул мелоксикама, нимесулида и этодолака на течение синдрома плечелопаточного периартроза. Использовались таблетированные формы препаратов в стандартных дозировках. Исследование проводилось на 86 больных (50 женщин и 36 мужчин) не имеющих высокого риска развития желудочно-кишечных заболеваний, среднего воз-

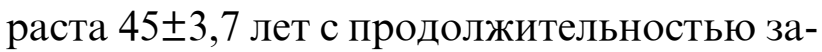
болевания 2-5 месяцев. Средняя оценка боли по визуально-аналоговой шкале (ВАШ) составила 7,2 1,6 . Ограничение подвижности и болезненность околосуставных тканей нами было оценено по специально разработанной 10-бальной шкале: « $\operatorname{good}(\mathrm{G}) »-$

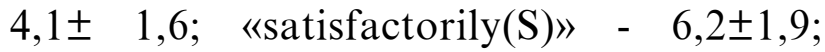

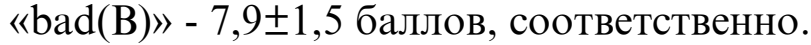

Оценка терапевтического эффекта проводилась через 14 дней приема лекарственных препаратов. Необходимо отметить, что статистически значимой разницы выявлено не было. Однако, величины, выявляемые по ВАШ составили: для мелоксика-

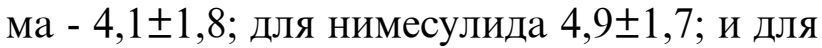
этодолака $4,5 \pm 1,5$, соответственно. Клинические параметры в виде болезненности парасуставных структур при пальпации и ограничение подвижности, выявленные нами в ходе повторного осмотра, были оценены следующим образом: для мелоксикама Э=3,2 $\pm 1,4 ; C=5,4 \pm 1,5 ; \mathrm{D}=7,1 \pm 1,6$; для нимесулида $Э=2,5 \pm 1,3 ; \mathrm{C}=5,0 \pm 1,5$; 


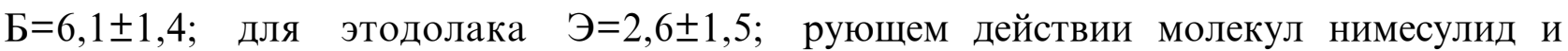
$\mathrm{C}=5,2 \pm 1,3 ; \mathrm{Б}=6,2 \pm 1,6$. этодолак. Подобные результаты дают ос-

Анализ полученных нами данных свиде- нования утверждать, что выбор ингибитотельствует о более выраженном анальгези- ра ЦОГ-2 в терапии плечелопаточного перующем эффекте молекулы мелоксикам и, риартроза должен исходить от выраженносоответственно, более выраженном проти- сти того или иного составляющего синдрововоспалительном и коллагеностабилизи- ма заболевания.

COMPARATIVE EVALUATION OF INFLUENCE OF COG-2 İNHIBBITORS ON THE COURSE OF SYNDROME HUMEROSCAPULOAR PERIARTHROSIS

Yagubov V.A.

«Saglam Aile» Medical Center

BAZU-KÜRӘK PERIARTROZU SINDROMUNUN GEDISSATINA SOG-2
INHIBBTORLARININ TOSIRININ MÜQAYISOLI QIYMOTLONDİRILMOSI

Yaqubov V.O.

«Sağlam Aila» Tibb Morkəzi 